\title{
Kaposi sarkomu nedeniyle radyoterapi uygulanan 14 hastanın değerlendirilmesi
}

\author{
Evaluation of 14 patients performed radiotherapy due to Kaposi sarcoma
}

\author{
Fatma Teke1, Zeynep Meltem Akkurt² ${ }^{2}$ Özgür Yıldırım', Memik Teke \\ Seyit Burhanedtin Zincircioğlu ${ }^{1}$
}

\section{ÖZET}

Amaç: Çalışmamızda Kaposi sarkomu (KS) tanısı nedeniyle radyoterapi (RT) uygulanan hastaların klinik özelliklerini ve tedavi sonuçlarını değerlendirdik.

Yöntemler: Çalışmaya Dicle Üniversitesi Hastanesi Radyasyon Onkolojisi Kliniği'nde 2005-2012 yılları arasında RT uygulanan KS tanılı hastalar dahil edildi. Tüm hastalara semptomların palyasyonu ve yaşam kalitesini arttırmak için farklı doz-fraksiyonasyon şemaları ile RT uygulandı. Birden çok bölgesinde lezyonu olan hastalara aynı veya farklı tarihlerde RT uygulandı. Hastaların radyoterapiye cevapları tam veya kısmi yanıt olarak kaydedildi.

Bulgular: KS nedeniyle radyoterapi uygulanan 14 hasta retrospektif olarak değerlendirildi. On dört hastanın toplam 22 farklı bölgesine RT uygulandı. Altı hastada $(\% 27,3)$ iki ayrı bölge ışınlanırken, yalnız bir hastada $(\% 4,5)$ üçüncü bölge olarak glans penisteki lezyona RT uygulandı. Işınlamalarda $6 \mathrm{MV}$ ve $10 \mathrm{MV}$ foton enerjileri ile $6 \mathrm{MeV}, 9 \mathrm{MeV}$ ve $12 \mathrm{MeV}$ elektron enerjileri kullanıldı. Foton ışınlamalarında homojen doz dağılımı elde etmek için su fantomu veya bolus materyali kullanıldı. Uygulanan RT dozu toplam 22 farklı bölge için medyan 800 cGy (800-3000 cGy) idi. RT fraksiyon sayısı medyan 1'di (1-10). Tedavi yanıtları değerlendirildiğinde $4(\% 18,1)$ bölgede stabil hastalık mevcuttu. Sekiz $(\% 36,4)$ tedavi bölgesinde kısmi cevap sağlanırken, $10(\% 45,5)$ bölgede de tam cevap elde edildi. Dört $(\% 57,3)$ tedavi bölgesinde RT' ye bağlı ayaklarda ve bacaklarda akut dönemde yaygın lenfödem gözlendi. İki $(\% 28,7)$ bölgede ise ağrı komplikasyonu mevcuttu.

Sonuç: RT, KS lezyonlarının palyatif tedavisinde uygun ve etkili bir tedavi rejimidir. RT ile cilt lezyonlarında mükemmel cevap oranları elde edilebilir. RT sonrası lezyonlar ve kaşıntı gibi şikayetler kaybolabilir. Ağrı, ödem gibi yan etkiler destek tedavi ile giderilebilir.

Anahtar kelimeler: Kaposi sarkomu, radyoterapi, doz-fraksiyon şeması

\begin{abstract}
Objective: In our study, we evaluated the clinical characteristics and outcomes of treatment in patients with Kaposi's sarcoma (KS).

Methods: The patients undergoing radiotherapy (RT) because of the KS between the years 2005-2012 in Radiation Oncology Department of Dicle University Hospital were included. All patients underwent RT with different dose-fractionation schemes to increase quality of life and to palliate the symptoms. Patients with lesions in multiple regions underwent RT in the same or different dates. Responses to radiotherapy were recorded as complete or partial response.
\end{abstract}

Results: Fourteen patients received radiotherapy because of $f \mathrm{KS}$ were evaluated retrospectively. Twenty two different regions of 14 patients underwent RT. Only one patient $(4.5 \%)$ was performed RT to glans penis as a third region while performed to the two regions in six patients $(27.3 \%)$. At irradiations, $6 \mathrm{MV}$ and $10 \mathrm{MV}$ photon energies with $6 \mathrm{MeV}, 9$ $\mathrm{MeV}$ and $12 \mathrm{MeV}$ electron energy were used. Water phantom or bolus material was used to obtain a homogeneous dose distribution in the photon irradiation. RT dose administered to a total of 22 different regional was median 800 cGy (Range: 800-3000 cGy). Median number of RT fractions was 1 (Range: 1-10).

When treatment response were evaluated stable disease was present in the $4(18.1 \%)$ regions. Partial response was achieved in eight $(36.4 \%)$ regions, complete response in 10 $(45.5 \%)$. RT-related common lymphedema in the feet and legs was observed in the four $(57.3 \%)$ regions in the acute period. Complication of pain was present in two $(28.7 \%)$ regions.

Conclusion: RT is an appropriate and effective treatment regimen in the palliative treatment of KS lesions. Excellent response rates of skin lesions may be obtained by RT. Lesions and symptoms such as itching may be lost after RT. Side effects such as edema and pain may be relieved by supportive treatment.

Key words: Kaposi's sarcoma, radiotherapy, dose-fractionation scheme

${ }^{I}$ Dicle Üniversitesi Tıp Fakültesi Radyasyon Onkolojisi AD. Diyarbakır, Türkiye

${ }^{2}$ Dicle Üniversitesi Tıp Fakültesi Dermatoloji AD. Diyarbakır, Türkiye

${ }^{3}$ Dicle Üniversitesi Tıp Fakültesi Radyoloji AD. Diyarbakır, Türkiye

Yazışma Adresi /Correspondence: Fatma Teke,

Dicle Üniversitesi Tıp Fakültesi Radyasyon Onkolojisi AD. Diyarbakır, Türkiye Email: doktorfatmateke@gmail.com

Geliş Tarihi / Received: 10.03.2015, Kabul Tarihi / Accepted: 18.06.2015

Copyright @ Dicle Tıp Dergisi 2015, Her hakkı saklıdır / All rights reserved 


\section{GÍRIS}

Kaposi sarkomu (KS), insan herpes virüsü 8 (HHV8) enfeksiyonu ile ilişkili olabilen nadir görülen vasküler bir tümördür. İlk kez 1872 yılında Moritz Kaposi adlı dermatolog tarafından "Çoklu İdiopatik Hemorajik Sarkom " olarak tanımlanmıştır [1]. Mavimsi kırmızı veya koyu kahverengi plak ve nodüller ile karakterize olup özellikle alt ekstremitelerin distalini, siklıkla da topuk ve ayakları tutar. Visseral tutulum da görülebilir. Alt ekstremite lezyonları yavaş yavaş proksimale doğru ilerler. Kaposi sarkomu; klasik, epidemik (AIDS ile ilişkili), endemik (lenfanjiopatik ve iyatrojenik olmak üzere başlıca dört tipe ayrılır. Klasik KS (KKS) öncelikle Akdeniz kökenli Yahudiler, İtalyanlar ve Yunanlılarda ve özellikle yaşlı erkeklerin alt ekstremitelerinde görülür [2-4].

KKS Türkiye'de görece yaygındır. Kaposi sarkomunun bulguları bölgeye spesifik olmakla birlikte eğer lezyon ayakta ise ağrı, şişme ve yürürken veya çorap giyerken rahatsızlık nedeniyle hastaların yaşam kalitesini olumsuz etkilemektedir.

Kaposi sarkomunun tedavisi esasen palyatiftir. Kaposi sarkomunun özellikle yaygın yüzeyel cilt lezyonları radyoduyarlıdır [5]. Radyoterapi(RT) KS için; minimum toksisite oranları ile yaşam kalitesini arttıran faydalı bir tedavi şeklidir. Farklı enerji çeşitleri ile değişik fraksiyonlarda uygulanır. planlama, teknik ve doz hala tartışmalıdır [6]. Özellikle el ve ayaklarda doku düzensizliği nedeniyle RT uygulanırken homojen doz dağılımı elde etmek zor olduğundan bolus materyalleri kullanılır [7]. Su; kolay bulunur ve uygulanabilir olması yanı sira doku eşdeğer özelliği nedeniyle de güvenilir olduğu için bolus materyali olarak kullanılır. Biz bu çalıșma ile radyoterapi uygulanan KS tanılı hastaların klinik özelliklerini ve tedavi sonuçlarını değerlendirmeyi amaçladik.

\section{YÖNTEMLER}

Çalışmaya Dicle Üniversitesi Hastanesi Radyasyon Onkolojisi Kliniği'nde 2005-2012 yılları arasında radyoterapi uygulanan Kaposi Sarkomu tanılı hastalar dahil edildi. Hastaların cinsiyeti, yaşı, lezyonun histopatolojik özellikleri, human immunodeficiency virus (HIV) serolojisi, immün supresif durum, organ transplantasyon öyküsü, RT başlama, tanı, nüks metastaz ve son kontrol veya ölüm tarihleri, RT uygulanan bölge, RT doz ve fraksiyonları, RT cihazı, enerjisi ve uygulama tekniği, RT yan etkileri ile varsa uygulanan diğer tedaviler hasta dosyaları ve hastane arşivindeki bilgiler incelenerek retrospektif olarak değerlendirildi. Dermatolog tarafindan muayene edilen ve klinik olarak KS düşünülen hastaların cilt lezyonlarından biyopsiler alınarak histopatolojik inceleme ile kesin tanı veya muayene ile klinik tanı konuldu. Viseral organlarda tutulumu araştırmak için, KKS tanısı alan hastaların abdominal ve toraks bilgisayarlı tomografisi (BT) çekildi. BT görüntüleri bir radyoloji uzmanı tarafindan visseral tutulum açısından değerlendirildi. Klinik muayene ve görüntüleme yöntemleri sonucunda hastalar, evre I makülonodüler cilt lezyonları, evre II infiltratif cilt lezyonları, evre III lokal ileri hastalık ve evre IV yaygın hastalık olacak şekilde KKS evreleme sistemine [8] göre evrelendi.

Tüm hastalara ağrı, kaşıntı gibi semptomların palyasyonu ve yaşam kalitesini arttırmak için RT uyguland1. Hastalar RT süresince haftada bir kez RT yan etkilerinin değerlendirilmesi amaciyla kontrol edildi ve varsa bulgular not edildi. Birden çok bölgesinde lezyonu olan hastalara aynı veya farklı tarihlerde RT uygulandı. Her iki el, aynı taraf el ve kol veya her iki ayak ve/veya bacak veya aynı taraf ayak ve bacağa aynı zamanda ve aynı su fantomu kullanılarak RT uygulanması tek tedavi bölgesi olarak kabul edildi. RT tamamlandıktan 45 gün sonra tedavi yanıtı değerlendirildi ve ardından ilk yıl her üç ayda bir, sonraki yıl altı ayda bir ve daha sonrasında yılda bir olmak üzere hastalar takip edildi. Hastaların radyoterapiye cevapları tam veya k1smi yanıt olarak kaydedildi. Tam cevap diyebilmek için ağrıda belirgin azalma ve pigmente KS lezyonlan1nın semptomlarında belirgin iyileşme kriter kabul edilirken; lezyonların gerilemesi ve ağnının azalması kısmi cevap kabul edildi. Lezyonlar değişmeden kalmışsa stabil hastalık olarak not edildi. Tedavi s1rasında veya tedaviyle tam veya kismi cevap elde edildikten sonra lezyonlarda büyüme, ağrı, şişme gibi şikayetlerde artış olması hastalık progresyonu veya rekürrens olarak kabul edildi.

Çalışmada elde edilen bulguları değerlendirmede, istatistiksel analizler için SPSS (Statistical Package for Social Sciences) for Windows 13.0 programı kullanıldı. 
Çalışma verileri değerlendirilirken tanımlayıcı istatistiksel metotların (Ortalama, Standart sapma, frekans) yanı sıra niteliksel verilerin karşılaştırılmasinda ise Fisher's Exact Ki-Kare testi kullanıldı.

\section{BULGULAR}

Çalışmamızda Dicle Üniversitesi Tıp Fakültesi Hastanesi Radyasyon Onkolojisi Kliniği’nde 20052012 yılları arasında Kaposi Sarkomu tanısı nedeniyle radyoterapi uygulanan 14 hasta retrospektif olarak değerlendirildi. Bu 14 hastanın toplam 22 anatomik bölgesine RT uyguland. Her bir hastanın bir, iki veya üç ayrı bölgesine aynı veya farklı tarihlerde radyasyon verildi. Hastaların medyan yaş1 65 'ti (40-85). On dört hastanın ikisi kadın, on ikisi erkekti ve kadın/erkek oranı 1/6 idi. Hastalar HIV seroloji ve HIV için risk faktörlerine göre değerlendirildi. Hiçbir hastada transplantasyon öyküsüne rastlanmazken yalnızca bir hastada HIV serolojisi pozitifti.

KS nedeniyle 14 hastanın toplam 22 farklı bölgesine RT uyguland1. Altı hastada $(\% 27,3)$ iki ayrı bölge 1şınlanırken yalnız bir hastada $(\% 4,5)$ üçüncü bölge olarak glans penisteki lezyona RT uygulandı. Glans penise $9 \mathrm{MeV}$ elektron ile 3x400 cGy fraksiyonasyon şeması kullanılarak toplam $12000 \mathrm{cGy}$ RT verildi. Ayrıca bu hasta RT öncesi immünoterapi almıştı. Yirmi iki bölgenin 3'ü $(\% 13,6) 6 \mathrm{MV}$, 13 'ü $(\% 59,2) 10$ MV foton enerjileri ile tedavi edilirken; 2'si $(\% 9,1) 6 \mathrm{MeV}$, 3’ü $(\% 13,6) 9 \mathrm{MeV}$ ve 1'i (\%4,5) $12 \mathrm{MeV}$ elektron enerjileri ile 1şınland. Foton 1şınlamalarında homojen doz dağılımı elde etmek için kullanılan su fantomunun kalınlığı medyan $16 \mathrm{~cm}(6-20 \mathrm{~cm})$ idi. Yalnızca bir hastada bolus materyali kullanıldı ve kalınlığı $0.5 \mathrm{~cm}$ idi. Uygulanan RT dozu toplam 22 farklı bölge için medyan 800 cGy (800-3000 cGy) idi. RT fraksiyon say1s1 medyan 1'di (1-10). Tablo 1 hastaların RT doz ve fraksiyon şemalarını göstermektedir.

Tablo 1. Radyoterapi doz ve fraksiyon şemaları

\begin{tabular}{cc}
\hline $\begin{array}{c}\text { Tedavi alanlarının sayısı (n=22) } \\
\mathbf{n}(\%)\end{array}$ & $\begin{array}{c}\text { Fraksiyonasyon } \\
\text { şemaları }\end{array}$ \\
\hline $14(63,7)$ & $1 \times 800 \mathrm{cGy}$ \\
$5(22,8)$ & $10 \times 300 \mathrm{cGy}$ \\
$1(4,5)$ & $3 \times 400 \mathrm{cGy}$ \\
$1(4,5)$ & $3 \times 500 \mathrm{cGy}$ \\
$1(4,5)$ & $8 \times 300 \mathrm{cGy}$ \\
\hline
\end{tabular}

Radyoterapi sonrası hastaların çoğu takipsiz olduğundan takip süreleri ve sağkalımları değerlendirilemedi. Fakat hastalar ilk y1l boyunca takiplere düzenli geldiklerinden RT'ye cevap ve akut yan etkiler değerlendirilebildi. Hastaların lezyonları ayaklarda, ayak bileklerinde, ayak plantar yüzde, bacaklarda, ellerde, inguinal bölgede, üst uylukta ve glans peniste idi. Anatomik olarak düzgün yüzeydeki veya küçük lezyonlar elektron enerjileri ile 1şınlanırken, homojen doz dağılımının elde edilemeyeceği ayaklar, eller, bacaklar gibi düzensiz yüzeyli bölgeler su fantomu kullanılarak foton enerjileri ile tedavi edildi. Tedavi yanıtları değerlendirildiğinde $4(\% 18,1)$ bölgede stabil hastalık mevcuttu. Sekiz $(\% 36,4)$ tedavi bölgesinde kısmi cevap sağlanırken, $10(\% 45,5)$ bölgede de tam cevap elde edildi.

Radyoterapinin akut toksisiteleri, RT sirasinda ve sonrasında yapılan takipler kaydedildi. Dört $(\% 57,3)$ tedavi bölgesinde RT' ye bağlı ayaklarda ve bacaklarda yaygın lenfödem gözlenirken, bir (\%14) hastanın da ayak tabanında yanma hissi şikayetine rastland1. İki $(\% 28,7)$ bölgede ise ağrı komplikasyonu mevcuttu. Bütün yan etkiler destek tedaviyle kontrol altına alındı. Diğer hastaların tedavi bölgelerinde belirgin radyasyon toksisitesine rastlanmad1. Cevap oranları ve RT komplikasyonları Tablo 2 de gösterilmektedir.

Tablo 2. Tedaviye cevap oranları ve radyoterapi yan etkileri

\begin{tabular}{lc}
\hline Tedaviye cevap ( $\mathbf{n = 2 2}$ bölge) & İlk $\mathbf{1}$ yılda $\mathbf{n}(\mathbf{\%})$ \\
\hline Tam cevap & $10(45,5)$ \\
Kısmi cevap & $8(36,4)$ \\
Stabil hastalık & $4(18,1)$ \\
\hline Akut yan etkiler (n= 7 bölge) & $2(28,7)$ \\
\hline Ağrı & $4(57,3)$ \\
Ödem & $1(14)$ \\
Yanma hissi & \\
\hline
\end{tabular}

\section{TARTIŞMA}

KKS sıklıkla 40-70 yaş Akdeniz erkeklerinde görülen, prognozu diğer tiplere göre daha iyi seyreden ve Türkiye'de nadir görülen diğer tiplere kıyasla daha yaygın olan bir neoplazmdır [2-4]. Bizim hastalarımızın da bir $(\% 7,1)$ tanesi AIDS ile ilişkili olmak üzere diğer 13 ‘ü $(\% 92,9)$ KKS idi. Çalışmamızda hastaların medyan yaşı 65 (40-85) olup 
ikisi kadın, on ikisi erkekti. KKS s1klıkla cilt lezyonlariyla karakterize olup viseral organ tutulumu nadirdir ve hastalığın klinik seyri sırasında ortaya çıkabilir [9]. Bizim olgularımızda viseral organ tutulumu olan hasta yoktu, tanı anında hepsi yalnızca cilt tutulumuna sahipti. Lezyonlar çoğunlukla alt ve üst ekstremitelerde idi.

KS tedavisi; lokal eksizyon, kriyoterapi, kemoterapi, immünoterapi ve radyoterapi gibi farklı modaliteler ile olabilmektedir [10,11]. Bu modaliteler arasında en sık kullanılan, en etkin kontrol sağlayan güvenilir tedavi şekli RT' dir [5,7,11-14]. KS'nin yaygın yüzeyel cilt lezyonları oldukça radyoduyar11 olduğundan tam cevap oranları yüksektir $[5,15]$. RT farklı enerji çeşitleri ile değişik fraksiyonlarda uygulanmakta olup planlama, teknik ve doz hala tartışmalıdır [6]. Lo ve ark. [5] yaptıkları çalışmada tek fraksiyonda 800-1200 cGy veya farklı fraksiyonasyon ile eşdeğer dozda RT uygulandığında \%93 oranında tam cevap elde ettiklerini rapor ettiler. Becker ve Bottke [15] yaptıkları çalışmada RT ile KKS semptomlarıly başetmede \% 90' dan fazla cevap ve $\% 70$ tam remisyon oranları ile oldukça başarılı olduklarını rapor ettiler. Onlar, çalışmalarında, farklı doz şemalarıyla etkili tedavi sağladıklarını ve kutanöz lezyonlarda 2 Gy/frk ile 30-40 Gy dozların etkili olduğunu söylediler [15]. Biz de farklı fraksiyonasyon şemalarıla RT uyguladığımız 22 bölgenin $\% 45,5$ 'inde tam cevap, \%36,4'ünde de k1smi cevap elde ettik. çalışmamızda RT sonrası lezyonlarında gerileme olmayan, stabil hastalığ devam eden iki hastada RT fraksiyonasyonu 1x800cGy iken diğer ikisinde 10x300 cGy idi. Bizdeki tam cevap oranlarının literatüre göre daha düşük olmasının, lezyonların çok yaygın olmasından kaynaklanabileceği düşünüldü.

Daha çok ekstremitelerde gözlenen KKS tedavisinde RT uygularken ekstremitelerin düzensiz yüzeylerinden kaynaklanan doz heterojenitesini ortadan kaldırmak için ya su fantomu veya farklı kalınlıklarda bolus materyali kullanılmakta ve böylece homojen doz dağılımı elde edilebilmekte veya dozun ciltte toplanması sağlanabilmektedir. Saw ve ark. [7] da ekstremiteleri su bazlı bolus kullanarak çeşitli foton enerjileriyle 1şınlamışlardı. Bizim çalışmamızdaki hastalarda da, birinde kalınlığ $0.5 \mathrm{~cm}$ olan bolus materyali kullanılmak üzere, ekstremite lezyonlarının çoğunda kalınlığı medyan $16 \mathrm{~cm}$
$(6-20 \mathrm{~cm})$ olan su fantomu kullanıld1. Saw ve ark. [7] ekstremiteleri 1şınlarken $4 \mathrm{MV}, 6 \mathrm{MV}, 10 \mathrm{MV}$, ve $24 \mathrm{MV}$ foton enerjileri kullandılar ve $10 \mathrm{MV}$ ve üzeri yüksek foton enerjileri ile daha homojen doz dağılımları elde ettiklerini rapor ettiler. Biz yirmi iki bölgenin 3'ünü $(\% 13,6) 6 \mathrm{MV}, 13$ 'ünü ise $(\% 59,2)$ $10 \mathrm{MV}$ foton enerjileri ile tedavi ettik.

KKS tedavisinde RT genellikle iyi tolere edilmektedir ve yan etkiler nadirdir [14-16]. Caccialanza ve ark. [16] KKS nedeniyle RT uyguladiklar1 hastalarda tedavinin daima iyi tolere edildiğini, mukoz membran reaksiyonunun 1lımlı olduğunu, ağrının ise semptomların kaybolduğu veya iyileştiği terlerde var olduğunu rapor ettiler [16]. Akmansu ve ark. [17] yaptıkları çalışmada ayak bölgesindeki KKS lezyonlarına uygulanan palyatif RT sonuçlarını değerlendirdiler ve 17 bölgenin 2'sinde kuru deskuamasyon, 2' sinde ağr1, 5 bölgede yaş ve kuru deskuamasyon ve 8 hastada ise enfeksiyon, yaş deskuamasyon ve ağrı komplikasyonu rapor ettiler. Bizim çalışmamızda da hastaların RT 'ye tolerans1 gayet iyiydi. RT sonrası ödem $4(\% 57,2)$, ağr1 2 $(\% 28,6)$ ve yanma hisssi $1(\% 14)$ hastada gözlendi.

Sonuç olarak; RT, KS lezyonlarının palyatif tedavisinde uygun ve etkili bir tedavi rejimidir. RT ile cilt lezyonlarında mükemmel cevap oranları elde edilebilir. RT sonrası lezyonlar ve kaşıntı gibi şikayetler kaybolabilir Ayrıca tedavi toleransı oldukça iyidir. Ağrı, ödem gibi 1lımlı komplikasyonların ise destek tedavi ile üstesinden gelinebilir. Biz bu çalışma ile nadir görülen KS'nun RT'sinde kullanılan farklı doz-fraksiyon şemaları ile elde ettiğimiz tedavi sonuçlarını ve toksisitelerini sunduk. KS tedavisinde standart doz ve fraksiyonasyon şemas1nın belirlenmesi için daha geniş serilerle yapılacak prospektif çalışmalara ihtiyaç vardır.

\section{KAYNAKLAR}

1. Kaposi M. Idiopathisches multiples pigmentsarcom der haut. Arch Dermatol Syphilol 1892;4:265.

2. Mohanna S, Maco V, Bravo F, Gotuzzo E. Epidemiology and clinical characteristics of classic Kaposi's sarcoma, seroprevalence, and variants of human herpesvirus 8 in South America: a critical review of an old disease. Int J Infect Dis IJID Off Publ Int Soc Infect Dis 2005;9:239-250.

3. Schwartz RA. Kaposi's sarcoma: An update. J Surg Oncol 2004;87:146-151.

4. Weissmann A, Linn S, Weltfriend S, Friedman-Birnbaum R. Epidemiological study of classic Kaposi's sarcoma: a ret- 
rospective review of 125 cases from Northern Israel. J Eur Acad Dermatol Venereol JEADV 2000;14:91-95.

5. Lo TC, Salzman FA, Smedal MI, Wright KA. Radiotherapy for Kaposi's sarcoma. Cancer 1980;45:684-687.

6. Hamilton CR, Cummings BJ, Harwood AR. Radiotherapy of Kaposi's sarcoma. Int J Radiat Oncol Biol Phys 1986;12:1931-1935.

7. Saw CB, Wen BC, Anderson K, et al. Dosimetric considerations of water-based bolus for irradiation of extremities. Med Dosim Off J Am Assoc Med Dosim 1998;23:292-295.

8. Brambilla L, Boneschi V, Taglioni M, Ferrucci S. Staging of classic Kaposi's sarcoma: a useful tool for therapeutic choices. Eur J Dermatol EJD 2003;13:83-86.

9. Brenner B, Weissmann-Brenner A, Rakowsky E, et al. Classical Kaposi sarcoma: prognostic factor analysis of 248 patients. Cancer 2002;95:1982-1987.

10. Kirova YM, Belembaogo E, Frikha H, et al. Radiotherapy in the management of epidemic Kaposi's sarcoma: a retrospective study of 643 cases. Radiother Oncol 1998;46:1922.
11. Nisce LZ, Safai B, Poussin-Rosillo H. Once weekly total and subtotal skin electron beam therapy for Kaposi's sarcoma. Cancer 1981;47:640-644.

12. Holecek MJ, Harwood AR. Radiotherapy of Kaposi's sarcoma. Cancer. 1978;41:1733-1738.

13. Piedbois P, Frikha H, Martin L, et al. Radiotherapy in the management of epidemic Kaposi's sarcoma. Int J Radiat Oncol Biol Phys 1994;30:1207-1211.

14. Chak LY, Gill PS, Levine AM, et al. Radiation therapy for acquired immunodeficiency syndrome-related $\mathrm{Ka}$ posi's sarcoma. J Clin Oncol Off J Am Soc Clin Oncol 1988;6:863-867.

15. Becker G, Bottke D. Radiotherapy in the management of Kaposi’s sarcoma. Onkologie 2006;29:329-333.

16. Caccialanza M, Marca S, Piccinno R, Eulisse G. Radiotherapy of classic and human immunodeficiency virus-related Kaposi's sarcoma: results in 1482 lesions. J Eur Acad Dermatol Venereol JEADV 2008;22:297-302.

17. Akmansu M, Goksel F, Erpolat O. P, et al. The palliative radiotherapy of classic Kaposi's Sarcoma of foot region: Retrospective evaluation. Int J Hematol Oncol 2014;24:147152 